\title{
5
}

\section{Circle for Survival}

We invite you to the Seneca Army Depot, the U.S. point of departure for nuclear weapons to Europe. Stay for as long as you can, part of a day or several weeks. Bring your dreams, ideas, skills, resources and creativity to make the Encampment a powerful witness and a strong community. The Encampment will be our own creation. Join us.

- Resource Handbook

One of the crucial tasks as the planners set out to organize women for a summer of protest was somehow to make other women see value in spending time at the encampment. The problem was not just a matter of publicity and advertising, of getting the word out. Well before the encampment opened, news of its development had spread throughout the extensive nationwide network of feminist and peace groups. Instead, the problem was how to define and present the encampment so as to appeal to the diverse interests and concerns of these potential participants. Those already involved in antinuclear protests and peace activities had used a wide range of strategies (from prayer vigils, singing, and marching to civil disobedience and violent, destructive actions) toward a wide range of goals (from simply eliminating nuclear weapons to overthrowing the patriarchy) that were not always compatible. Moreover, many men were involved in these groups, and the decision to limit the encampment to women could be expected to create some antagonism. And despite talk of a "women's movement" as if it were a unified entity, there was no one group and no one set of principles and positions universally accepted by women who identified themselves as feminists or political activists.

The decision to limit the encampment to women came early in the 
planning, but it was not made easily. The debate on this issue illustrates some of the fundamental differences among the various types of women involved in the organization of the encampment. In one early meeting organizers discussed the role of men in the encampment, the definition of feminism, and the reasons for making the encampment a women-only action. They could not come to any consensus. Some argued that defining the camp as feminist might be more exclusionary than just calling it a women's camp. They were concerned that a lot of attention was being focused on the exclusion of males rather than on the development of something positive for women. Some women clearly did not want to exclude men completely and worked to have a separate public space on the encampment land where supportive men could gather to talk and provide help. One supporter, in a long letter, expressed her dismay, shared by many others, that male children over the age of twelve were to be excluded. "Dear Friends," she wrote,

It is a crystal morning in the mountains. Every green plant in the sun gleams iridescent and those in the shade sway gently, shaking off the lush dew. I fathom the message of the morning, gather a primrose, happy with its perfume, rub the wounded stem and pick some clover I will admire in the window before I dry it for tea. And I cry, for the earth I love so, angered that human beings have dealt with and are dealing so badly with her-and each other.

I have been an active, enthusiastic and creative participant in the group of Greater Burlington women organizing to support the Women's Encampment for a Future of Peace and Justice.

It was my idea to emblazon our leaflets with the words: "SEND MOTHER TO CAMP." I never expected the corollary to be: "But don't let her children visit her there-if they are boys."

The woman went on to explain that her two teenage sons, ages fifteen and nineteen, had been active in antinuclear protests since they were young, and the fifteen-year-old had been looking forward to coming to the encampment.

Jeremy cares very much about peace. Like many kids his age he wonders often out loud-if he has two minutes left-as part of life on earth. He's a teenager now, but his male hormones haven't persuaded him to bare his teeth and take guns. I'd like you to meet him.... He was so excited about Seneca. He thinks peace activists are his friends. And now he understands, there is nothing on earth he can do in some women's minds to be considered a friend. And that is sexism, not women's liberation. 
I never had a harder thing to say in my life than to tell him he wouldn't be allowed to visit me at the Women's Encampment. I told Jeremy a lot of women are afraid, that boys over twelve rape.

Jeremy offered to get a hundred letters saying he is absolutely opposed to violence of any kind. Would that do it?

... I raised my sons to be brothers in the work for peace and they are.

Unless males are raised this way, there will be no peace. Peace cannot be the issue for only part of the species, and the millions of young men around the world who resist the draft testify to this. The more than 60,000 ex-GIs who committed suicide after returning from Vietnam testify to a raping of their lives as well.

I close this letter, but not my mind, in the hopes that you haven't closed yours to the idea that sons and brothers can visit the wOMEN's ENCAMPMENT FOR A FUTURE OF PEACE AND JUSTICE. (June 29, 1983)

The encampment eventually agreed to define itself publicly as a womenonly activity and space. Men were not involved in the organization of the encampment or in the purchase or physical preparation of the land. When the encampment opened, men were allowed only on the front grounds; they were encouraged to support but not actually to participate in the protests. As the encampment proceeded through its first summer, this became even more of an issue for some of the women who were not involved in the initial discussions. As one woman explained in a letter she wrote after she returned home,

The march yesterday was invigorating, emotionally, spiritually and physically. Your courage and commitment is an inspiration, enough so that my husband and I attended the march. While I am committed to the same ends that you all are, I must speak to the issue of separatism that seems to have influenced so much of what you are doing

It is undoubtedly true that men have manipulated events that have led humanity to this point of confrontation and confusion and have perpetuated a reprehensible crime on the planet in spreading the horror of nuclear arms, but there is a new generation of men, and Sam [her husband] is one of them, who do not want to be "like their fathers," who are trying desperately to break free from the enslavement that the traditional male image implies. If we in our struggle for equality and freedom relegate our brothers to the position of "nigger," then what have we gained? Yet another oppressed class. By alienating those who wish to help and who have as much a vested interest in the outcome of the issues as we have, we will make the opposition stronger and will insure our own defeat. 


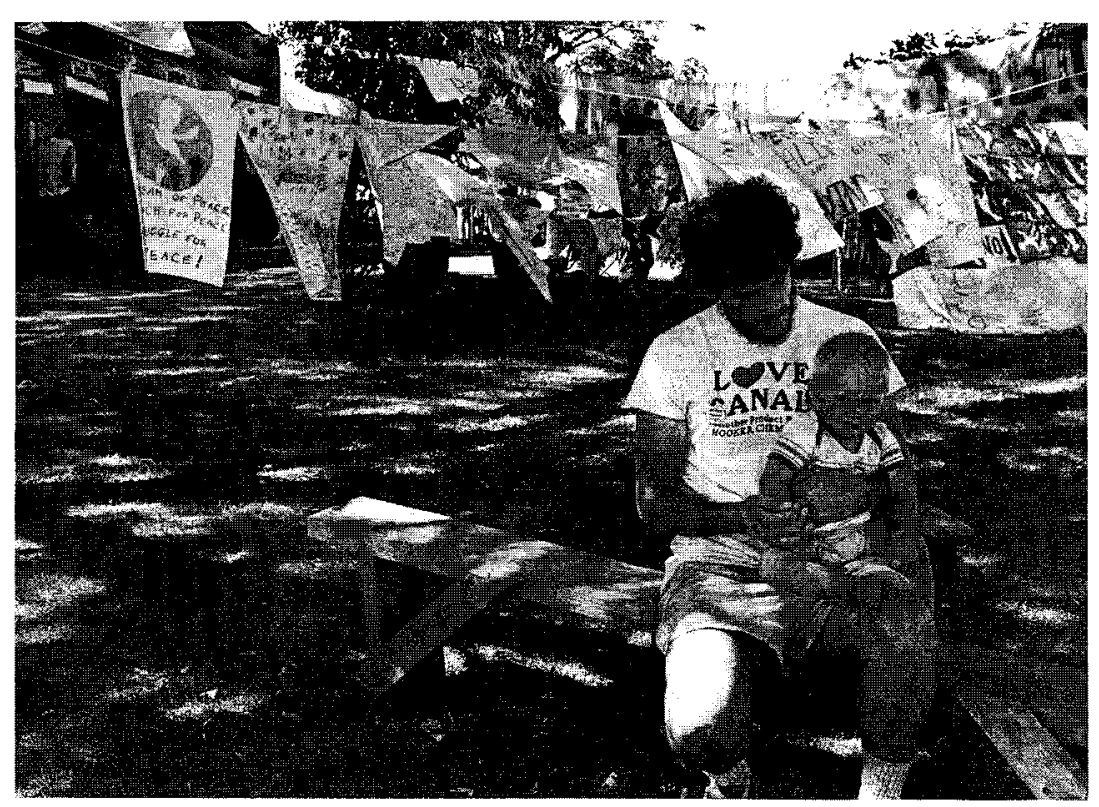

Man and son in encampment front yard

Please give thought to this question of segregation. Let's not put more people "on the back of the bus," but let's work together to guarantee our sons and daughters a future worth living and neighbors worth loving. (August 2, 1983)

The encampment was meant to be conceived as a safe place where women could work together without the physical, emotional, or mental stress that some considered inevitable in the company of males. Nevertheless, this foregrounding of gender as a major issue in the critique of the militaristic-patriarchal-nuclear establishment caused difficulty for many women who became involved in the encampment, particularly those who had close ties to men through marriage or motherhood, or whose political beliefs did not tolerate exclusion or separatism.

Many Encampment organizers and participants, however, believed that there are indeed substantial differences between male and female spheres of activity and interest and that women must provide solutions to the problems created by the male-dominated society. In the Resource Handbook, published as an orientation guide, several women explained their reasoning in a section titled, "Why a Women's Peace Camp?" (36). 
An action of this length without men ... allows for creativity and community unique within the American peace networks with the possibility of a totally new direction emerging from the acknowledgement of women's experience.

- Terry Faatz

It is a vast statement that no longer will women sit back and allow men to make the decisions alone which affect the entire globe.

-Rebecca Linsner

Throughout history, in all the world's warring, feminist process has never been used for conflict resolution.

- Helene Aylon

In this view, history and previous personal experience had shown that women needed to work apart from men to be most effective. The idea that men and women occupy different spheres has been debated in the women's movement for over a century (Bernard 198I). In recent years it has reemerged in feminist thought under the rubric of a "woman-centered" approach. Feminisms in the late 1960 s and early I 970 os were generally based on the recognition of gender differences, but these differences were seen as the source of women's oppression, and they were ascribed not to some psychological, biological, or social inevitability but rather to the patriarchal social and political system that relied, says Hester Eisenstein, on "the exaggeration and the maintenance of women's otherness from men" (I983:45).

The path to the successful resolution of this problem was seen as twofold: to deny the significance of these differences and to eliminate the notion that women were significantly different from men by providing women with equal opportunities and rights. This solution was thought possible through an approach that supported androgyny, "in which," Gayle Rubin writes, "one's sexual anatomy is irrelevant to who one is, what one does, and with whom one makes love" (1984:I69). The new rights and opportunities this approach promised were supposed to enable women to show that sexual differences were insignificant for determining what a person could become.

By the mid-I970s, many feminists were questioning this approach, in part because of new research in psychology, anthropology, history, and literature and also in part as a result of the direct challenges of feminist activists and lesbian feminists to heterosexism and patriarchy. In history, 
literature, and the arts, interest arose not only in evaluating the patriarchal representation of women in texts and visual works but also in revising the canons in these fields so that they included the contributions of women. These corrective measures relied on uncovering information about women's contributions and also necessitated a revaluation of the standards by which such contributions are judged. Literary critics debated whether there was such a thing as "women's writing" or a "women's style," challenging, if not reconstituting, the criteria by which literature was analyzed and judged (see Eagleton I 983 ; Moi I 985 ).

The interest in the previously excluded realm of women's lives fit well with the new focus in history, which began to turn from the study of great events and famous men to the study of the everyday lives of common people (Gies and Gies 1978; Ferguson et al. I986; Ginzburg 1982). In the art world, art by women became better known and feminist contributions began to challenge artistic canons and art history (see Broude and Garrard I982; Hess and Baker I973; in film: Kuhn I982, I 985 ; de Lauretis I 984).

In anthropology a similar trend manifested itself in cross-cultural research that focused on women. Women's activities in the "private," domestic sphere were shown to be as complex, meaningful, and significant as the male activities in the "public" sphere. Ideas about women's universal symbolic connection to nature and men's to culture were considered and discarded, but not before they influenced a large body of work that helped reveal the worlds of women (see Rosaldo and Lamphere 1974; Reiter 1975).

In psychology rereadings of Freud and other reconsiderations of psychic and sexual life (see Garner et al. 1985; Mitchell and Rose 1982) and female development (Chodorow 1978) led to a reevaluation of the specifics of women's lives and how they differed from men's. Psychologist Carol Gilligan investigated the features of this proposed female sphere of difference and has defined what she feels is a unique female moral sensibility that has developed in our culture. According to Gilligan's analysis of women's development and values, women have a strong sense of obligation to others which develops out of their social role as caretaker of the family. This enables them to understand the needs of others and consider their point of view; their caring and concern for other people makes them aware of the great emotional cost of success achieved through competition (I982:I5-I6). Unfortunately, they develop these qualities in a society that places value on just the opposite behavior patterns. As a result women are caught in a contradiction between what they have come to believe and value, and what they are told is worthwhile. It is just this contradiction that a woman-centered approach hopes to diffuse. 
Like Gilligan, many feminists were emphasizing the differences between men and women rather than dismissing them in the late 1970 s and I 980 ; they were interested not in minimizing these differences but in understanding and defining them. Eisenstein explains, "Instead of being considered the source of women's oppression, these differences were now judged to contain the seeds of women's liberation." Rather than "a form of inadequacy and a source of inferiority, this view considered these differences to be a source of pride" $(1983: x i, 46)$. Women's activities are to be valued as highly and studied as seriously as men's. Moreover, women's particular strengths, values, and ideas are seen as a superior basis for the organization and execution of social activities. A woman-centered approach requires that society change to accommodate the women's sphere rather than that women accommodate themselves to the world as constructed by men.

The peace encampment organizers actively employed this womancentered approach with its unique male and female spheres and its privileging of women's contributions to social, cultural, and political life. The same values that Gilligan identified as "female" were considered the basis of the alternative world toward which the encampment was striving. As a result, in the "official" position of the encampment, feminism was to be defined as being woman centered:

Feminism is a value system which affirms qualities that have traditionally been considered female: nurturance of life, putting others' wellbeing before one's own, cooperation, emotional and intuitive sensitivity, attention to detail, the ability to adapt, perseverance. These traits have been discounted by societies which teach competition, violent conflict resolution, and materialism. Feminism insists that the qualities traditionally considered female be recognized as deserving respect and manifesting great power. These qualities need to be emphasized more so as to create a balance with the traditionally male attributes of assertiveness and effectiveness in the world. (Resource Handbook 1983:32)

The encampment was developed, then, as a place where these female qualities could be expressed and put into practice. Yet this seemingly straightforward attempt to define feminism as woman centered was the source of much internal dissension in the 1983 encampment.

Throughout the late winter and the spring, these issues were debated at large monthly organizational meetings in upstate New York cities and in New York City and at smaller satellite meetings throughout the North- 


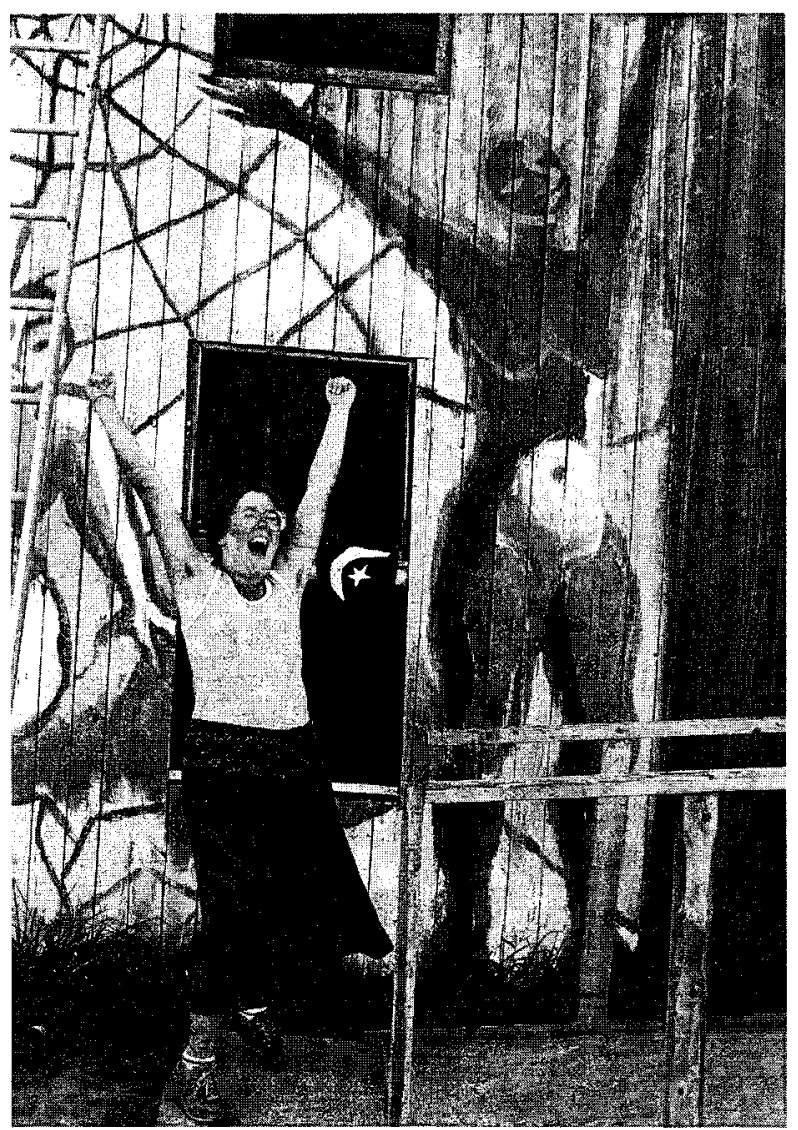

Encampment woman in front of painted barn

east. The meetings focused both on the logistics of setting up the campbuying or leasing land, raising funds, advertising, physically preparing the camping space-and on more philosophical issues related to the purpose of the camp, the development of a vision statement, and the refinement of a political agenda.

The farmland on which the encampment eventually came to rest was located in the winter of $1982-1983$. Some saw the circumstances surrounding the purchase as a good omen. The land was a worn-out farm that had been on the market for quite a while priced at about $\$ 45,000$. A woman from Rochester told the encampment organizers about the parcel, and some of them visited the owners, two women who had inherited the 
land from an aunt. The owners had already refused to sell the land at a reduced price to other potential purchasers, but the organizers were able to convince them that the "educational" camp they wanted to open would be worthwhile. The land was purchased for $\$ 37,500$ on May 23, I983, with money raised from donations and personal loans provided by concerned activists. Women began preparing the land in the spring in anticipation of a July 4 opening.

Like every group trying to mobilize masses of people, the encampment needed more than just a shared space and a formal organization; it needed a way of referring to itself as an entity. In order for members to perceive themselves as a group, they needed to share an identity that was supported by symbolic constructs and interpretive discourses. The encampment needed to create itself as an "interpretive community" whose shared strategies would organize the group's approach to meaning and action and define what was reasonable to say and do in that community.

The early encampment organizers did not necessarily see themselves as a nicely unified, coherent group that could easily explain itself to others. On the contrary, the monthly organizational meetings were making clear the divergent thinking, conflicting value systems, and varying hopes and expectations of those involved. Yet the women recognized the need to decide on an image or representation of themselves in order to communicate with others. This representation would influence not only the decisions about the running of the encampment and the development of protest actions but also all the verbal and visual information the encampment created, including T-shirts, posters, books, songs, and press releases.

It is the job of every organization to create a representation of itself that through repetitive use comes to seem a mirror of that group's actual constitution. This representation becomes the group's identity only if it gives some assurance of reflecting the real world; the representation created about and by the encampment was assumed to reflect the inner workings of that group. It was also designed to persuade other women to identify with this representation enough to attend the encampment and become actively involved in its promotion.

Representations, whether they are created by totalitarian agencies or feminists devoted to equality, are not disinterested images but powerful political tools that in a sense become more real than reality itself (Kappeler 1986:3). Representations are the currency we use in social exchanges; they stand in for more complex, contradictory, and inaccessible things. If a representation is to appear coherent, if some type of communication is to be successful, and if the discourse is to be controlled, representational 
forms must be simplified and edited. Thus any representation of a group necessarily involves the repression of difference within it (Jacobus I986: I 17; Meese I986:84).

This issue is quite problematic for a feminist group. On the one hand, feminism is guided by the principle that every woman should speak only for herself, that patriarchy has repressed important differences based on race, sexuality, ethnicity, politics, and religion, which women must now be allowed to voice. But difference is the greatest threat to representation because it brings up the possibility that the representation does not accurately reflect a stable reality. When a woman rejects the possibility of representation, when she says that it is impossible to state definitively who she is and how she should be interpreted, she certainly rejects authority (which is a positive outcome for feminism), but she also loses the possibility of taking a political stance. This failure to create a specific political agenda could not be permitted at the encampment, and any hesitations about the construction of a representation had to be put aside to allow for political action.

What is interesting, then, about the encampment's representation of itself is not whether it accurately reflected the makeup of this women's group but how it was employed for political purposes both within the encampment and with outsiders. In describing the content of the selfrepresentation this group created, therefore, I am more interested in understanding the representational process itself. The analysis and interpretation of the meanings of this specific representation are of interest only insofar as they enable us to consider the process and politics involved in the construction and use of that representation throughout the first summer of the encampment.

The encampment constructed a representation of itself through three means. The first means was the development of a name. During the early organizational meetings, the organizers referred to the encampment as the Women's Peace Camp or Women's Peace Encampment. They settled on a formal name at an April I983 meeting in Albany. The Third World Women's Caucus, a group of women concerned about women of color in "underdeveloped" nations, suggested that the word "justice" appear in the name in order to show that the encampment was concerned not only with peace but also with the social transformations necessary to create a peaceful world. The women debated whether to say "peace with justice," "justice with peace," or "peace and justice." One woman suggested Women's Peace Camp for a Just World without Weapons, but the participants finally decided on Women's Encampment for a Future of Peace and Justice. 
The second means of developing a self-representation was through the drafting of a vision statement that would express the encampment's goals and philosophy. The vision statement, which was to appear in all encampment literature and publicity, needed to be concise and straightforward. At several meetings the women discussed their hopes for the encampment. Many drafts were prepared, discussed, and edited before the following statement was formulated:

Women have played an important role throughout our history in opposing violence and oppression. We have been the operators of the Underground Railroad, the spirit of the equal rights movement and the strength of the peace movement. In I 590, the women of the Iroquois nation met in Seneca to demand an end to war among the tribes. In I 848 the first Women's Rights Convention met in Seneca Falls giving shape and voice to the Igth century feminist movement.

Once again women are gathering at Seneca-this time to challenge the nuclear threat at its doorstep. The Seneca Army depot, a native American homeland once nurtured and protected by the Iroquois, is now the storage site of the neutron bomb, and most likely the Pershing II missile and is the departure point for weapons to be deployed in Europe. Women from New York State, from the United States and Canada, from Europe, and, indeed, from all over the world, are committed to nonviolent action to stop the deployment of these weapons.

The existence of nuclear weapons is killing us. Their production contaminates our environment, destroys our natural resources, and depletes our human energy and creativity. But the most critical danger they represent is to life itself. Sickness, accidents, genetic damage and death, these are the real products of the nuclear arms race. We say no to the threat of global holocaust, no to the arms race, no to death. We say yes to a world where people, animals, plants and the earth itself are respected and valued.

The third means by which the encampment created a self-representation and presented it publicly was through the use of symbols. Symbols provide the means by which an organization can be "seen" (Kertzer I 988: 15 ). The anthropologist Victor Turner has shown in his work with symbolic systems that for any social group we can identify the dominant or focal symbols that "make visible, audible, and tangible beliefs, ideas, values, sentiments, and psychological dispositions that cannot directly be perceived" (Turner 1967:50). These focal symbols are multivocal, that is, they stand in for many different things and are thus "economic representations of key 
aspects of culture and belief" (ibid.). Although we should be aware of the dangers in assuming that symbols possess more uniformity in use and meaning than is possible with social beings, they are nevertheless a useful means through which to study how a group attempts to conceptualize and present itself.

Symbols have a great deal of work to do in a social group: they must maintain order, provide a social identity, and categorize people and ideas (Bolton $1988: 7$ ). In order to fulfill these needs, the peace camp organizers successfully employed two symbolic constructs, the circle and the web. These two focal symbols provided a consistent framework for the alternative, woman-centered world being developed and later acted out at the encampment. The peace encampment did not completely abandon the meanings of these symbols as they have been constituted by the dominant discourse. Instead, the women expanded and revalued these meanings as they applied the symbols to this alternative setting.

The circle was the first symbol borrowed from the dominant discourse for revision and use at the encampment. The encampment accepted the dominant discourse's technical definition of the circle and also employed the archetypal definition of the circle as the natural way, according to followers of C. G. Jung, for westerners to represent the self or psyche, a central place, wholeness, and the universe (Jung 1964). In Western discourse and social life, says Jung, this symbolization is played out most publicly in art, architecture, and the designs of cities-all of which employ circular patterns dependent on these meanings. The circle is also commonly used to represent cyclical, endless movement as in the movement of the sun and planets; it can also be seen as a circuit that eventually brings things back to their point of origin.

The women of the encampment greatly expanded the implications of these meanings of the circle in their efforts to define a woman-focused world. The circle was used to represent the female essence on the most basic, "natural," elementary level: it was the womb, the inner-oriented core of the female world. Many encampment organizers believed that all women possess this inner orientation, not just as a result of women's biological makeup but as a spiritual connectedness that all women share even if they are not yet aware of it.

Many of the encampment women had read the work of feminist philosopher Mary Daly, who has stated that sometimes when women first meet they feel that they have a psychic, spiritual connection (Daly I 978: $37 \mathrm{I})$. This uncanny experience confirms for the believer the notion that all women are connected simply by virtue of being female. Inner orientation 


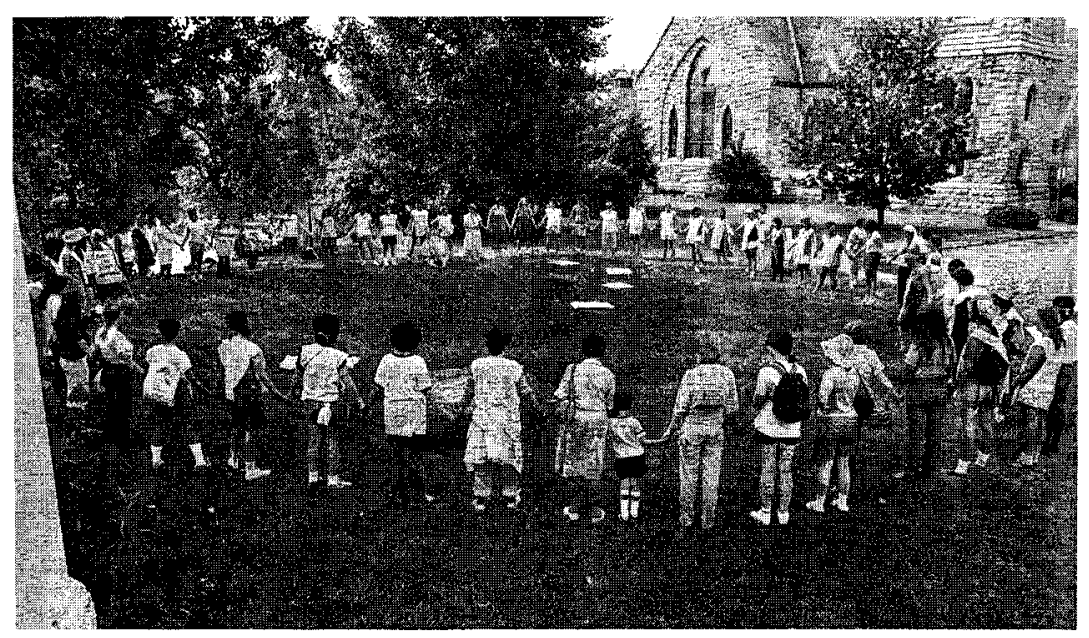

\section{Circle at beginning of March from Seneca Falls through Waterloo. Photo by Pam Quiggle}

is seen as the source of womanpower, "the power-from-within ... a power based on a very different principle from power-over, from domination" (Starhawk 1982:3). This shared inner orientation that defines the essence and power of femaleness is thought to bind all women together.

This approach is often critiqued as essentialist, that is, as promoting the idea that all women share a particular essence, or basic characteristics. Some feminists see this essentialism as dangerous because it duplicates the oppressive strategies of the patriarchy, which lumps all women together by claiming that all share a flawed nature. Nevertheless, some of the planners used the essentialist argument when they tried to explain why so many different kinds of women were moved to participate in the encampment. One woman explained:

A lot of women are more concerned with the world and the world's going to blow up and I think it struck a deep inner core. I can remember being in Ithaca and being out to dinner ... hearing this couple [at the next table] in their late forties or early fifties talking and arguing about the peace camp. And the woman was defending the peace camp and understanding the issue of why we had to be so rowdy to attract the press or why it was an all women's camp, the man just having no concept. And obviously the woman had never been there and never really had any direct contact but just from the media presentation she on 
a gut level understood. And I think it was that kind of inner place that the peace camp touched in women who had never thought about the issues or never thought about going to an all-women's space.

This statement certainly reflects this essentialist notion of shared womanhood, but essentialism was also used in another, more intricate way at the encampment. As Teresa de Lauretis (1990:5-6) has explained, many feminists use this idea of a female essence not to describe reality but as a utopian, idealist project that "re-visions" the world. Woman is defined not as a set of immutable characteristics but as a locus where different effects come together. The female body, together with particular dispositions developed through living as a female in a patriarchal culture at a specific historical point, forms women who are both similar and different. Perhaps the essentialism of the encampment should not be condemned as simpleminded and restrictive but should be celebrated for employing this utopian definition of female potential. The truly challenging as well as frustrating nature of the encampment was that it claimed it was possible to alternate freely between these aspects of essentialism.

The encampment came to be seen in the larger feminist-activist communities as one of the centers of women's activities and energies, as a protecting womb that, as one organizer stated, "everything comes from and grows out of." The life-protecting aspect of the womb/circle parallels the peace-keeping activities that all women are said to find a "natural" part of their lives. As the encampment Resource Handbook explained: "For the last I0,000 or so years, women have generally served society as peacemakers. Women have cleaned up after manmade wars. They have tended the wounded, comforted and cared for the widowed. They have been the peacemakers within the family, and within the community. Women have raised and trained the young, formed and staffed the charities, healed the sick, assisted at births and tended the dying. Women have enriched and enhanced the living-out of human lives, in all ages and in all regions of the world" (30).

That the circle-as-womb was a particularly powerful representation of this inner orientation and all-female connectedness can be seen in an event that took place to advertise and celebrate the peace camp. At the 1983 Michigan Women's Music Festival, an annual summer gathering that celebrates women's (particularly lesbian) "culture," a symbolic space was created to represent the women's encampment, which was taking place concurrently. The place created at the music festival consisted of pillowcases decorated with women's dreams of peace, hung on lines to create 
a secluded enclosure, a protective, womblike structure made of dreams. This same ritual space representing the encampment was later transported to New York City and set up on a sidewalk. According to one of the organizers, "The women all slept inside of this little womb that they made for themselves out of these pillowcases and that was their only protection from the outside world."

This space was used in Michigan for "centering", a process that is supposed to establish a sense of location, to place a person spiritually, physically, and emotionally. Centering is an important concept for the woman-focused world, both for the individual and the group. As one organizer explained: "It is important no matter what kind of organizing we do to immediately establish what the center is, because the center gives protection. It is where the gathering happens for support, for healing, for nourishment ... and on land that we go on we try to find the center of that land ... [so as to] draw energy from that physical space."

The encampment contrasted its use of such concepts as the circle, centering, the womb, and circular movement to the use of the line, phallus, and linear movement by the dominant, patriarchal discourse the women were opposing. The line is used in this discourse to represent the path of a moving point, of progress or movement away from the point of origin. In common everyday usage, time is generally seen as linear, not cyclical, and the ideas of power and progress derive from linear, hierarchical organizations, not circular ones. The circle indicates uncertainty, indefiniteness, a lack of direction. For example, people who fail to progress toward their goals are said to be "going around in circles" instead of "making a straight line" for something; "walking the straight line" indicates a sense of purpose, direction, and sobriety. A cogent argument has a "line of thought" backing it, whereas an incoherent one is based on "circular reasoning." A circle of friends is a casual, egalitarian group, but a line, ladder, or chain of command differentiates people by power, wealth, or status.

The encampment considered the line a phallic symbol and associated it with the power exercised and controlled by males. The circle was seen as a more generalized female symbol associated with cycles (of menstruation and the moon); with the vagina, womb, and breasts; and with softness and roundness. (We can note in continuing the analogy that a circle is never hard, but a "hard line" can be taken in an argument; also that hard women are masculine and soft men effeminate.) Linearity and masculinity, along with the concomitant feature of differential access to power and authority, were used as a foil by the encampment as the focal symbols expressing the essence of patriarchal discourse. 


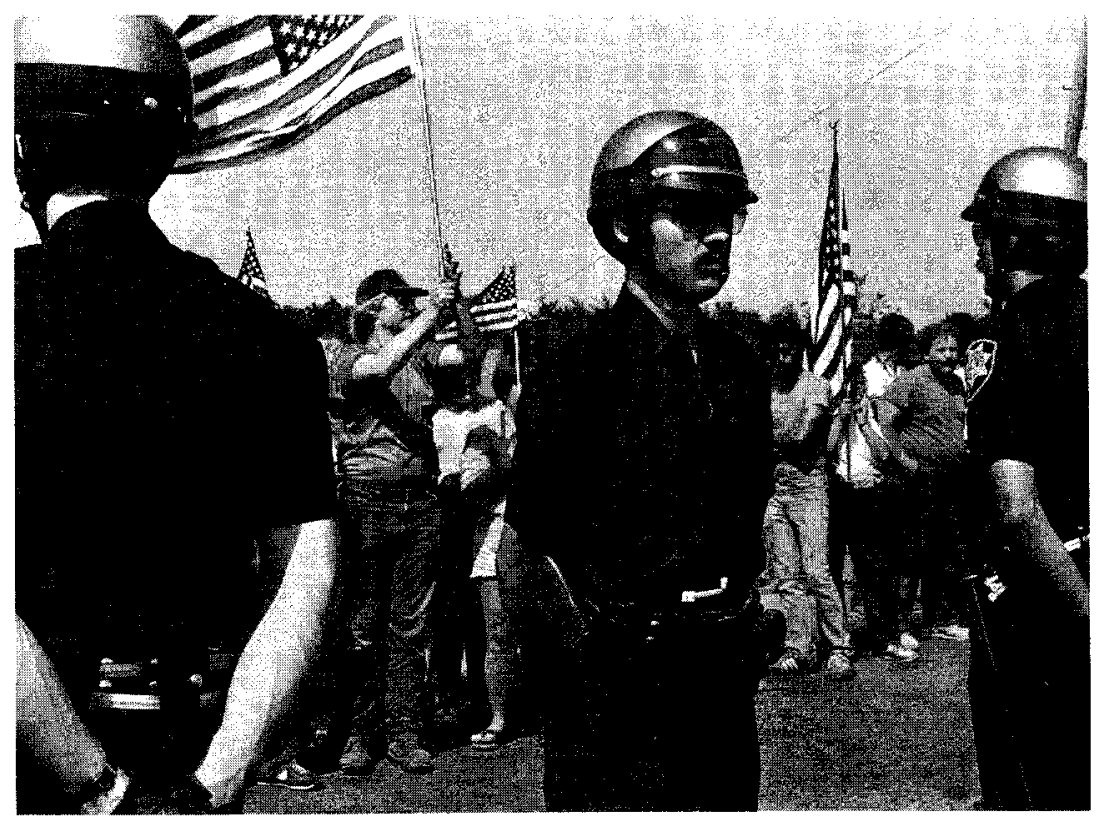

Police line with counterdemonstrators. Photo by Pam Quiggle

Surely not all the women who came to the peace encampment believed in the ideas behind these symbols or were even familiar enough with them to decide whether they agreed with their use. But because many of the organizers claimed all women naturally shared an affinity with this symbolic orientation to the circular, they developed an entire community around these ideas, and any woman coming to the encampment could not help but be exposed to this view. The model based on the circle was played out for general consumption in several ways at the encampment. For example, it was used as the organizational principle for the meetings held as a regular part of encampment activities. Ideally, participants sat in a circle, all of them face-to-face, speaking to one another as members of the same community. The meeting circle had no leader, only a facilitator who moved the meeting along but did not dominate the discussion.

The entire alternative model represented by the circle was also exemplified by the attempt to base decisions on consensus rather than majority rule. As it was phrased in the Resource Handbook, "The fundamental right of consensus is for all people to be able to express themselves in their own words and of their own will. The fundamental responsibility of consensus is to assure others of their right to speak and be heard. Coercion and 
tradeoffs are replaced with creative alternatives and compromise with synthesis" $(42)$. Consensus, then, was seen as an active step toward a new approach to dealing with other people, one that rejected aggressiveness and coercion and advanced cooperation and mutual support. During the exchange in which consensus is sought, discussion proceeds around the circle as the participants attempt to come to mutual understanding and agreement. Although in reality decisions were often made on the basis of who could survive the longest in meetings that stretched on for hours or days, the ideal of consensus guided policy making.

One direct expression of the belief in the protecting powers of the circle is found in a song called "Circle for Survival," which was sung at many protest actions throughout the summer. Based on a song by Linda Hirschorn, this version was circulated by the encampment women on mimeographed sheets.

\section{Chorus}

Circle for survival, circle for the right not to disappear into the everlasting nite Circle for survival, circle for the right not to disappear into the everlasting nite

Circle all the bases, circle day and nite enclose them in a wall of sacred strength and sight let the people see them for what they really are let the people know they threaten our home star

\section{Chorus}

Circle all the strip mines, circle day and nite Circle all the people, lend them all our might Circle all the rapists, the men and their machines Circle all the ones who take away our dreams

\section{Chorus}

Circle all the pueblos, keep them safe from harm Circle native people with hearts and minds and arms They're fighting for their homelands, what little they have left It's up to us to help them rectify the theft

\section{Chorus}


The circle is our weapon, the circle is our tool

The circle is our heartspace, the circle is our school

the circle is our kiva, the circle is our truth

the circle is our power against the ones who rule

\section{Chorus}

While singing this song, women would form a circle, their arms around one another. The circles they formed during ritual protests at the army depot often provided a striking visual contrast to the lines of military personnel also present. Ritual circles held at the encampment itself were used to create a sense of community and tranquillity, especially after long and difficult meetings. Circling was also used during depot protests as a means of protection in confrontations with violent or bothersome males. A group of women, to diffuse the confrontation and separate the problem male from the other women, would form a circle around the man while attempting to talk to him and move him away from the area. The circle both protected and empowered the women and helped to contain the dangerous male force. During several confrontations with local residents, encampment women sat on the ground in tight circles that showed their unity and also protected them. Circles of women were even used to form a privacy screen for women who needed to urinate during long protests in areas that had no restroom facilities.

The use of the circle as a focal symbol by the encampment made sense for many reasons, most notably because it was easily opposed to what was seen as the patriarchal mode of linearity, hierarchy, and power-over. It should also be noted that the circle is an important aspect of feminist spirituality rites, and many women at the encampment, especially camp organizers, embraced and practiced these religions to varying degrees. The circle, explained Starhawk, a feminist writer who defines herself as a witch and priestess of the Old (Goddess) Religion, helps define a ritual time and space, setting the participants apart from everyday life. Casting a circle "is the formal beginning of the ritual, the complex 'cue' that tells us to switch our awareness into a deeper mode" (Starhawk r 979:58). The circle is also considered significant because it is an "energy pattern that contains whatever power we raise so that power can be focused and concentrated. It protects us from intrusion, forming a barrier to any unwanted forces" (ibid.). The ritual circle, then, like the encampment itself, was a means of participating in an alternative world with an out-of-the-ordinary set of rules. 
The web was another focal symbol developed and used at the encampment. Its popularity in feminist circles is at least partly attributable to the Spider Woman stories of Native Americans, which some feminists take as proof of women's power in other times and places (see Mullett 1979). Like the meanings of the circle, the web's particular meanings in the dominant discourse were transferred to the encampment and revalued in the process. The most common referent for the web in the dominant discourse is the spider's web, which acts as a trap to capture insects. The spider is often associated with the female because of its weaving and spinning. The habit of some female spiders of devouring their mates after sex also has developed as an element of our common discussions of spiders. A web can refer to the complex machinations of the mind or imagination, as in a web of lies or a web of intrigue, but the symbol does not seem to have been used this way at the encampment. The term web is also gaining popularity as a way of referring to networks of people or organizations in both the feminist and nonfeminist worlds.

At the women's peace encampment, the symbol of the web elaborated upon the alternative cultural model represented by the circle and was the means by which the influence of the circle's model was extended. Nevertheless, although used to construct and support the same "culture," the two symbols do not duplicate each other. The circle is the local organizational principle, whereas the web is the operationalization of this principle, the extension of the circle into the larger world.

The factors tying the second symbol of the web to symbol of the circle derive from the physical properties of the spider's web. The circle forms the center of the spider's web but does not share its physical properties; it is only the beginning, and the web, not the circle, keeps growing bigger, extending far beyond the center. This process was seen as analogous to the organizing of the encampment, which was carried out initially by a core group of hired staff who eventually gave over the responsibility for the operation to a more diffuse group called a work web. One organizer explained,

Well, you have a circle in the center of the web. The web came to the Encampment really early.... When we were burnt out and needed some kind of help and guidance, a group of women came and set up a work web... so that the center, the center being the hired staff, did not have to bear the full brunt of the responsibility. The center was rapidly becoming like the center of a spider's web and losing its core and you have an empty circle. But in a spider's web, the circle does not support the rest of 
the web. By the time the encampment opened, we as the circle core could not support the rest of that web, and then the work web started to function and started to feed nourishment into the circle once again.

A further analogy with the spider's web involves the function of the web as a means of getting women involved in the issues represented by the circle. This worked in a positive sense when women became "captured" or "engulfed" by the web of the encampment experience: "That happened a lot at the Encampment. Women were going to the Encampment for a weekend, and they went for a weekend and stayed for a month. Or they went for a day and stayed for a week, or they would continuously come back.... There was a woman who was a therapist who went home and told all her patients to come to the camp, that they didn't really need her. Closed her practice, has never practiced since and came to stay at the Encampment all summer. .. . She's still there every now and again."

The web also functions as a less benign trap when dealing with the "enemy," those elements that threaten the web and refuse to participate in its process: "The way women build webs. . . I'm thinking of an enemy coming into the web and getting stuck, then the spider comes and eats that enemy.... you just eat them, get the web around it, eat it up." This concept was visualized in the encampment Handbook ( $1983: 18$ ) by an illustration in which President Reagan and his nuclear weapons are captured and controlled by the web of feminist and peace protests (see figure 2). The actual constitution of the web also provides protection from these outside enemy forces because, one organizer said, "every part is connected to another part, and even if one part is taken out the web still exists.... it can become fragmented but still maintain its strength." She visualized the entire women's peace movement this way-at times it may appear fragmented but all the connections are still there, ready to be put into action. These ties were described as invisible: "Lines [were] coming into the encampment, getting ready to take off and once it took off, all these invisible links went back out to new people and changed lives," expanding the web in the process.

The web provided another explanation for and unifying image of the large number and diversity of women who came to or supported the encampment. According to one of the planners, women were "organizing in communities thousands of miles away without ever having had any contact with us, just that they heard this encampment was happening." One story told by the organizers stressed this connection to groups of which they were not even aware: 


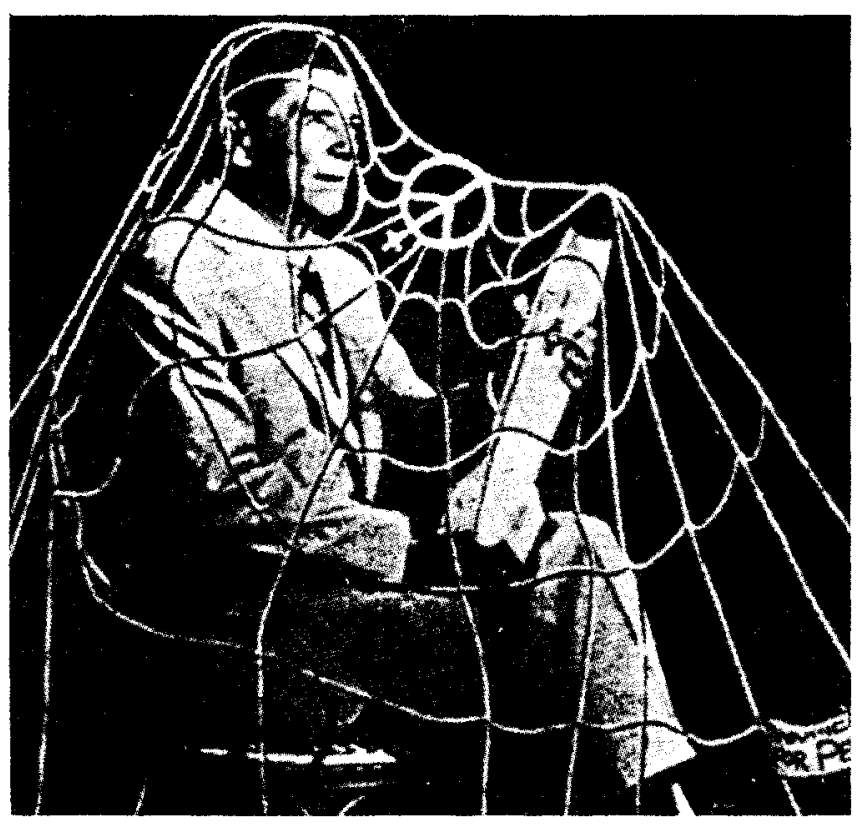

Figure 2. Image of Ronald Reagan in a web

There was this nursing home and these women couldn't go [to the Encampment] so they got together and had a sewing circle and made a peace lamb. [Other] women [from the same community in Minnesota] went on August ist to the big demonstration and they had this lamb that they were carrying because it was from their community. And they got to the fence [of the army depot] and it came time to climb the fence and everybody got so excited that they threw the lamb over the fence. And when these women in the nursing home heard this, they got so excited they were clapping their hands and squealing and said, "We did it, We did it," that they themselves had sent a representative to the base and it had gotten thrown over the fence and they were ecstatic over the whole thing. This was a symbol of their efforts and their community work and they just loved it. And they never went to the encampment, they just heard and sent their proxy sacrificial lamb.

This story points to some of the same concepts of connectedness with the web that are also emphasized with the circle-that all women have natural ties to one another that will express themselves given the chance. These ties can be demonstrated when women weave ritual webs, con- 


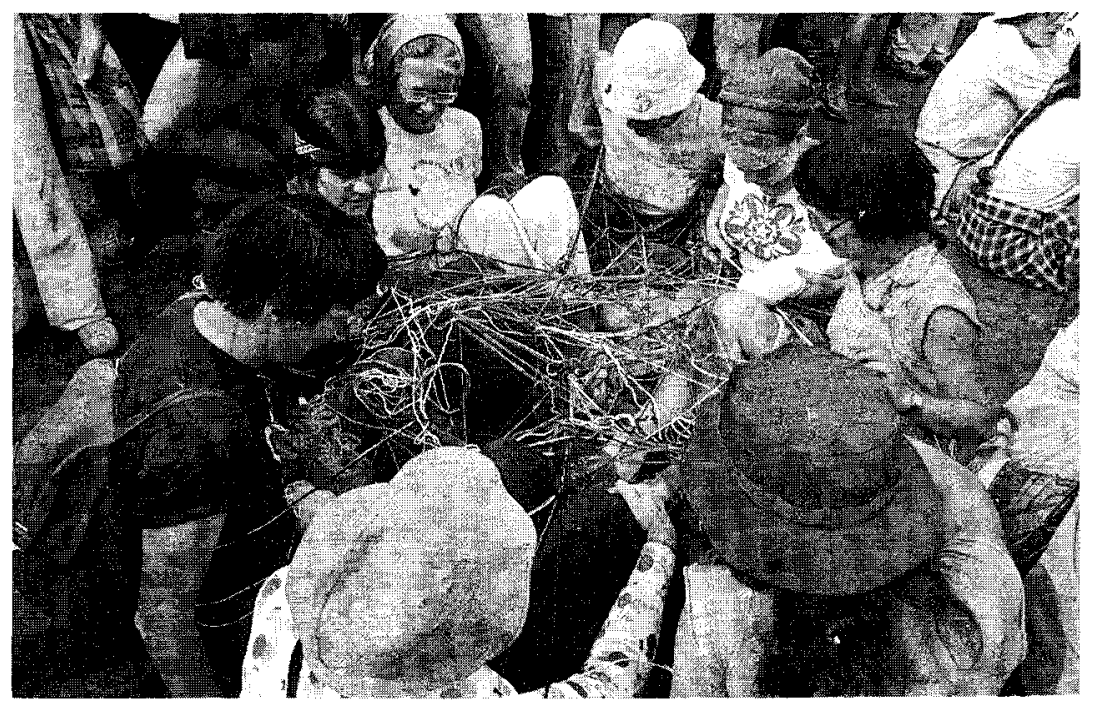

Women joined by yarn web during protest. Photo by Pam Quiggle

structed by groups of women, each of whom holds a piece of yarn or string which they weave randomly, interlocking and overlapping the yarns to form a weblike structure. These webs can be quite small or can cover extensive areas, and often they are made as part of a larger ritual. The women do not plan the web out ahead of time but use their "spiritual ties" as a guide. Women perceived these connections as both intellectually understood and emotionally felt.

The web, like the circle, also was used at the encampment to represent an organizational process that takes its strength from what participants believed was women's unique approach to the world. The web again endorses a nonlinear approach. Several of the organizers interviewed expressed this concept. For one, the web represented "a different way of structuring things. It is not like planning how to build a pavilion [a building being constructed on encampment land], put one board here and one down there. It comes out a different way." Another continued: "The spirit leads to the building of it, as opposed to some kind of mental plan.... when we're doing a web and we connect, we don't know if we are going this way or that way. But no matter what way you go, it is part of it and that just encompasses all the different realms that women are coming from." Another added: "[That is] the one thing that being involved in the encampment has taught me. I've always heard people say, 'You have to 
trust in the Goddess.' But it really felt with the encampment that if you do what you're supposed to be doing, things will fall into place and it may not be until one second before absolute calamity but usually someone pulls through at the right minute."

The web not only connected physical beings, it also provided a symbol for tying together all the issues that were seen to stem from a patriarchal, male-dominated society. The idea was that none of the issues-the nuclear arms race, child care, poverty, battering, rape, or racism-were separate. They were all related to the power relationships set up by patriarchal institutions. In a chapter titled "Everything Is Connected," the encampment Handbook addressed many of the economic, social and racial issues related to militarism, stating that "past anti-war movements [i.e., male-dominated ones] have failed to address patriarchy as a premier cause of militarism" (1983:19). The press release announcing the opening of the encampment also made this point, indicating that, "The Women's Peace Encampment will not only make a statement against the Pershing II missiles and other nuclear arms, but will also make a statement against the military buildup in general, which is irresponsibly taking away from human needs." One of the participants in a workshop at the 1983 encampment expressed the same concept: "If we're women and we're thinking holistically rather than linearly, then we have to see that they're all connected and we have to work on them all at once because they're all connected."

The web, like the circle, had physical and visual manifestations at the encampment. A yarn web was woven on the back of the main house and a large web was painted on the side of the barn behind the main house. During protests, yarn webs, often incorporating personal possessions, photographs, and memorabilia, were woven into the fence around the Seneca Army Depot. The personal possessions and photographs were indications of things that a woman did not want to lose in a nuclear waroften the pictures were of children and friends. This type of web symbolism was inspired in part by a ritual that took place at the 1980 and $198 \mathrm{I}$ Women's Pentagon Action, a protest against expanding militarism in the United States, and by a protest at the Vermont Yankee nuclear power plant. In both places women wove yarn webs across the entrances to these sites to close them symbolically.

Work at the encampment was organized by "work webs" in which each woman was expected to participate. These webs not only were the organizing principle of work crews but were also promoted as a way for women to get involved with the other women at the encampment. Women 


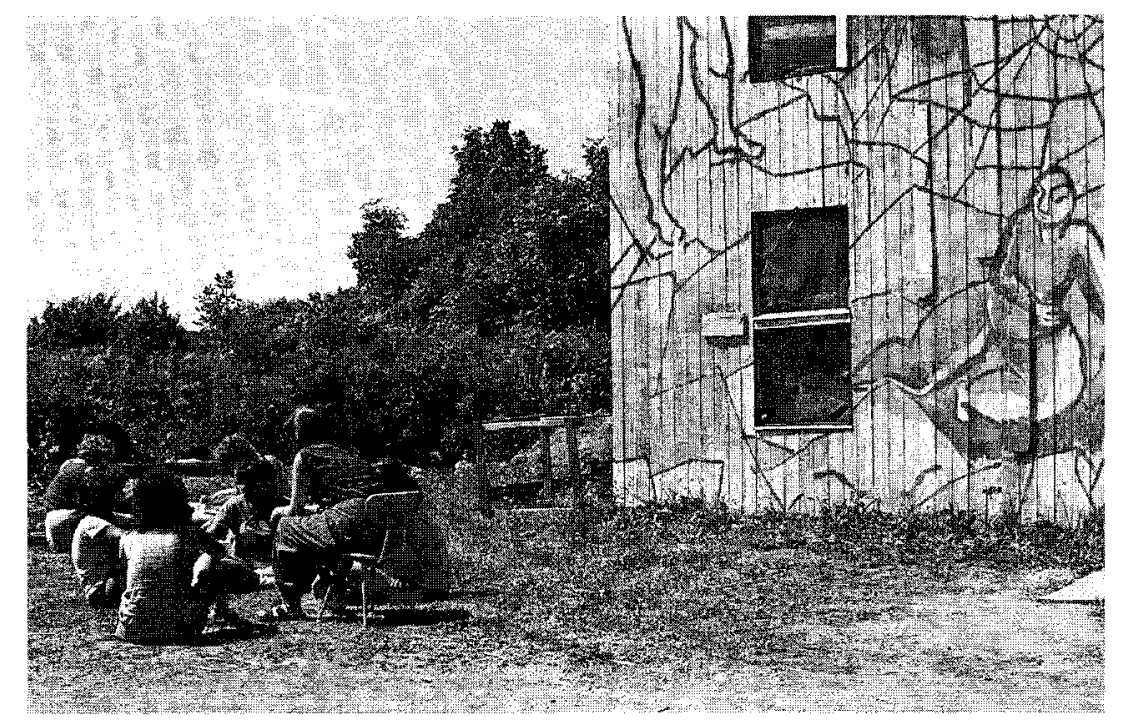

Encampment meeting in front of web painting

were expected to sign up daily for "webs" that involved three hours of labor in the areas of security, garbage recycling, child care, food preparation, dinner cleanup, reception, gardening, healing/emotional support, office/clerical work, general maintenance and construction, and media work.

These two interrelated symbols, the circle and the web, provided part of the self-representation created by the women's peace encampment. Both were successful focal symbols that had multiple applications in the visual, rhetorical, organizational and ritual activities of the camp. Taken together they helped form and express the alternative world that the encampment was striving to develop and live out, a world that was woman centered rather than male dominated. Its major metaphors were circular rather than linear, and it was seen as egalitarian rather than hierarchical. It proposed to celebrate the life-giving womb, peace, protection, cooperation, and caring rather than the phallic patriarchal world of destruction, war, violence, and competition.

This new world was not being proposed through a complete redefinition of dominant discourse symbols. As we have seen, the meanings of the circle and web in the dominant discourse were quite similar to the meanings employed by the encampment women, who attempted to revalue 
femaleness conceptually without changing the definition of femaleness and female qualities, as had been standard feminist practice in the past. Rather, the symbols of the circle and the web were used to present an alternative view that did not entirely contradict dominant discursive notions of male and female but instead put more value on qualities perceived as female in the dominant discourse. Because the circle and the web were marginal, not focal, symbols in the mainstream culture, their meanings were flexible enough to be used successfully to revalue the female sphere in an innovative way. Yet they were familiar and accessible to most women without extensive education, and they fit well with the representation the encampment organizers wanted to create-a picture of women working together naturally to better the world.

The development of these meanings of the circle and web certainly contributed to the establishment of a basically unified identity for the encampment. Such stable signs help establish group identity and a workable representation by creating shared meanings. Yet at the same time the use of symbols can be seen as conservative and somewhat unfeminist in that they tend to suppress difference and plural interpretations. The female circle with its connections, continuities, and equalities represents a world that is supposed to be in direct contrast to the linear, patriarchal world of hierarchies, dominance, and inequalities. Yet the privileging of such terms as "center," "source," "meaning," "holism," "origin," and "unity" suggests a repetition of the desire for coherence, unity, and authority so severely critiqued when they are used in patriarchal discourses. Symbols often play a conservative role in discursive battles as each faction tries to articulate its own positions and those of the other positively and clearly. Symbols can be the first and last line of defense in self-definition, but they also lock one into a stance that denies or ignores important differences and dissenting views. Donna Haraway (1985:73) has suggested that speaking from such a position-one in which shared group identity has been so specifically and perhaps rigidly established-can be a poor political strategy for women because it merely reproduces the essentialist categories and static representations that women now suffer.

But political necessity often seems to dictate that feminists not question their own discursive practices when they attempt to dismantle those of the enemy. The encampment was caught in this trap, forced to negotiate between utopian idealism and practical political action while experimenting with new theoretical possibilities. The use of the web in conjunction with the circle perhaps represents an attempt to avoid all the pitfalls of representation, for the web, which opens up meanings and makes connections that 
might seem unthinkable, tempers somewhat the essentialism and erasure of difference promoted by the circle. It is only through the intertextuality suggested by the circle in conjunction with the web that the encampment had the possibility of acting out any deconstructive feminist goals.

A third symbol, the labrys, a double-bladed ax (see figure 3), was introduced early into the encampment representation, but this one, unlike the circle and web, was neither well known nor well accepted. Mary Daly in her "metadictionary," which attempted to uncover words hidden in "patriarchal dictionaries," defined the labrys as "the symbol of gynocratic power in Crete as it was among the Lycians, the Lydians, the Amazons, the Etruscans, and even the Romans ... found in the graves of Paleolithic women of Europe, buried 50,000 years ago" (1987:142). The labrys was seen as a sign of women's power, especially the power derived from association with other women.

For many of the encampment organizers, the labrys was a familiar and welcome symbol used by lesbians. As one organizer explained about the labrys and lesbian identity, "If someone was wearing a labrys and you were in a totally strange city, you would know that woman was a lesbian. One of the things that happened with the camp was that a lot of the women who were straight women who had never been involved with lesbians or with feminists before became exposed to lesbian symbols and have begun to incorporate them into their own reality." When the labrys-a symbol one woman suggested sends the forceful message "Don't mess with me!"-was put on an early encampment sign, several women felt it would provoke violence from the local community. It was, however, the association with lesbianism that made the labrys unacceptable for the women creating the early representations of the encampment and for those who came to the encampment later.

Lesbianism became a controversial issue. It was the focus of much of the antagonism between the encampment and the community and among encampment members themselves. Many women at the encampment considered lesbianism an important aspect of their alternative, nonpatriarchal world. Since the encampment was designed to be a physically, socially, and spiritually safe place, women were encouraged to express all aspects of their femaleness freely. For many women, identifying as a lesbian was the most important feature of this revised identity. The encampment Handbook provided this explanation:

The Women's Encampment is meant to be a place of safety for all women, a place where women can gather strength to protest the nuclear 


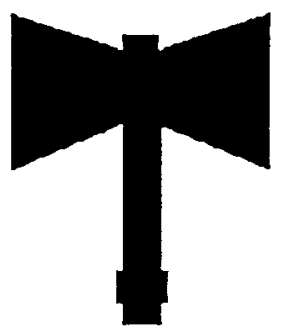

Figure 3. Labrys, the double-bladed ax

threat. Women of all races, classes, religions, ethnic backgrounds, sexual preferences, are encouraged and expected to participate. It is with this in mind, that we briefly discuss the issue of homophobia (fear or discomfort of lesbians and/or gay men) as it pertains to lesbianism and as it relates to the visions of the encampment. One vision of the encampment is that it will provide an environment where women are free to be themselves. For lesbian women, this means a place where lesbians can feel safe and unself-conscious about their sexual choices, a place where lesbianism is appreciated as one of the many life choices that women make. Another vision of the encampment is that it will be a model for ways that women can work together, a place where women can share plans for a peaceful world. In such a world, all would be welcome; lesbians would not have to hide. (I2)

This public acknowledgment and acceptance of lesbianism as simply a variation in the spectrum of women's behavior focused much attention on issues of homosexuality at the encampment. The encampment, by setting up a community where "lesbians would not have to hide" was challenging the invisibility of lesbians and gay men that was demanded by patriarchal discourse. The images of homosexuality that predominated in the patriarchal discourse were seriously attacked by encampment lesbians who wanted to replace patriarchal representations with their own interpretations of lesbian life.

Homosexuality, explained Vito Russo in a study of the representation of gays in mass-media films, is viewed in the dominant discourse as "something you 'do' in the dark and like a bad habit it can be broken" (198I:9I). Until I974 the American Psychiatric Association listed this "bad habit" as a mental disorder, an imbalance in the mental and physical 
condition, "a failure rather than a variant of sexual reciprocity, an asymmetry which disrupts what are held to be immutable categories" (Watney I 987:I 26). Many churches, particularly those associated with fundamental Christianity, still condemn homosexuality as unnatural and sinful. Most communities have refused to pass ordinances banning discrimination on the basis of sexual preference, although most states have at one time or another proposed such laws.

In 1977 the battle over one such community ordinance became national news, and during this time the discourse about homosexuality was articulated nationwide. The spokesperson for the dominant discourse was Anita Bryant, a former Miss America contestant, orange juice promoter, and self-proclaimed expert on homosexuality. In January 1977, the Dade County (Florida) Commission enacted an ordnance that would ban discrimination against gays in housing, employment, and public accommodations. It was the first gay rights ordinance passed by a southern city, and within weeks Bryant's group was working for its repeal (Shilts I982: I 55). During the fight against the ordinance, Anita Bryant came to symbolize the country's conservative attitude toward homosexuality, which she labeled as evil, sinful, and deviant, "a cancer on the soul of society" (Bryant and Green I978:125). When Dade County voters repealed the ordinance in June 1978, Bryant said, "Tonight, the laws of God and the cultural values of man have been vindicated. The people of Dade County-the normal majority—have said, 'Enough, enough, enough'" (Shilts I982: I 57).

The discourse on homosexuality has been further articulated more recently in relation to Acquired Immune Deficiency Syndrome. This AIDS discourse didn't have extensive nationwide dissemination until the death of homosexual actor and leading man Rock Hudson in 1985 . In 1983 the disease was just beginning to be recognized. Nevertheless, the basis for this discourse was available long before Hudson put AIDS on the front page. This representation of homosexuality and AIDS "fastens on what is most frightening and alluring in the other-for example, gay men's fantasized freedom from sexual and family constraints-and projectively makes it the sole marker of identity" (Grover I987:24). Thus homosexuality represents the body, social contracts, sexuality, morality, the self, and reproduction in crisis (Beaver 1981:99), and AIDS is interpreted as the result of challenging the natural and legal order.

Lesbians have the additional difficulty of being subsumed under a category that takes the gay man as its reference point. As Jan Zita Grover (1987:25) explains in discussing the perceptions of lesbians in relation to 
AIDS, lesbians are lumped with gay men, blacks and Hispanics, and intravenous drug users. Like these known "risk groups," they are designated as "essentially and socially different from the 'general population"” and so are believed to be AIDS carriers, even though as a group lesbians have among the lowest incidence of AIDS.

The discursive representation of lesbians is not as definitive as that of gay males. In a sense, lesbianism is unthinkable in a patriarchal society because gender identification not only is the proper identification with one's biological sex but also "entails that sexual desire be directed toward the other sex" (Rubin 1984:I65). Gay males are thought to enact this scenario, according to the dominant discourse, by taking on stereotypical male and female roles, but lesbians, because of their greater invisibility, have not had these precise representations constructed about them yet. Lesbians are an unwritten text onto which any number of scenarios can be projected. Lesbians, according to Anita Bryant are "anti-male, antiwhite, antifamily, anti-church and anti-American from start to finish" (Bryant and Green $1978: 124)$. When they do appear, lesbians consistently serve as a foil for the "normal": "In a society so obsessed with the maintenance of sex roles and the glorification of all things male, sissies and tomboys served as yardsticks for what was considered normal behavior" (Russo I98 I:63).

But the lesbian also presents a different kind of threat from that posed by the gay male. The male homosexual can be neutralized by the claim that he maintains the patriarchal system of sexual and interpersonal relations (despite the shift in the sex of his partners) because gay male relations are thought to duplicate the male-female relations of patriarchal society (Shilts 1982; 1987). Lesbians, however, can be seen as more threatening not just because they break out of the culturally constructed gender categories that specify proper female and male relations but because they challenge the heart of that categorization-the acceptance of the male as normal and the standard against which all others are measured. The result is an unacceptable confusion not just of gender roles but also of power relations, and a violent reaction against these threats is often attempted by the patriarchal society.

Underlying the privileging of lesbianism at the encampment was the concept of the lesbian as being woman centered. As Hester Eisenstein explains, lesbians "escaped from, and indeed, renounced, the definition of 'woman' as secondary, derivative, or second-best to men. That is, they accorded to one another that primacy and importance that most women accorded only to men" (1983:52-53). 
Lesbianism has been used within the broader feminist world (although with much disagreement) as a symbol of this orientation of all women who are woman centered, even if they are not sexually involved with other women. According to lesbian writer Jill Johnston, "The word [lesbian] is now a generic term signifying activism and resistance and the envisioned goal of a woman committed state" (in Eisenstein 1 983:48). Adrienne Rich has also expanded the meaning of lesbian and lesbianism beyond "clinical" definitions to include "the sharing of a rich inner life, the bonding against male tyranny, the giving and receiving of practical and political support" (I984: 4I7).

The difficulty with these expanded definitions of lesbianism within the peace encampment (as in the larger feminist community) is that not all women, heterosexual or lesbian, could agree on how to employ this concept. For some separatist lesbians, it was unacceptable to apply the term lesbian to women who continued their social or sexual relations with men. For feminists who were homophobic or who did not want feminism to be narrowed to a discourse on sexual preference, this association of the encampment with a lesbian identity was also unacceptable. When women publicly displayed affection to each other or otherwise engaged in what the local community defined as lesbian behavior, the public message was that lesbianism was condoned, or even promoted by the women's encampment. Yet the encampment itself could not agree on just how to work lesbianism into its self-representation. The labrys, then, as a third symbol of the encampment's operations and philosophies was problematic partly because it was basically unfamiliar and also because the encampment participants could not generally accept it as representative of all of them.

Participants developed and reworked the encampment's selfrepresentations throughout the summer of 1983 . The circle and web remained important aspects of that representation in 1983 and for years afterwards; the labrys became an accepted symbol after the first summer, when the encampment became more of a lesbian community. Not surprisingly, the local communities often misunderstood or disapproved of how the encampment represented itself, and the symbols of that representation became weapons in the discursive battles that ensued. 